\title{
0 racional e o razoável: Aristóteles e o trabalho hoje
}

\author{
Hermano Roberto Thiry-Cherques*
}

\section{Resumo}

As mudanças por que passam o trabalho e as formas de administrá- lo têm evidenciado um divórcio entre a literatura técnica sobre o tema e a esfera real da economia e das organizações. Neste artigo, procuramos construir uma ponte entre o racionalismo do mundo acadêmico e o realismo do mundo efetivo das organizações, mediante a recuperação de três temas aristotélicos: 0 da sabedoria prática, 0 do conhecimento como fonte de poder e 0 da valorização do propósito do trabalho em detrimento do seu processo.

Palavras-chave :. trabalho; racionalidade; administração; Aristóteles.

\section{Abstract}

The changes that occur in work and ways of managing it have been showing a divorce between technical literature about the theme and economics and organization's real sphere. In this paper we draw a line between academic world's rationalism and organization's effective world realism through the recovery of three aristothelic themes: practical knowledge, knowledge as power source and valorization of work's purpose to the detriment of its process.

Keywords: work, rationalization, management, Aristotle

O pensamento estratégico da atualidade se caracteriza pela reformulação do projeto normativo do liberalismo competitivo. As visões integristas, construtivistas e dialógicas, que regeram a virada do século, estão dando lugar a modelos e procedimentos mais confiáveis. O pragmatismo teórico e o tecnicismo utilitário estão sendo substituídos pela atitude crítica e pela ação ponderada.

No plano do binômio racionalidade/trabalho, a busca de fundamentos substantivos de ação tem trazido à luz alguns temas do realismo aristotélico. Em contraposição ao hermetismo ineficiente dos discursos econômicos e gerenciais do fim do século passado, esse realismo oferece uma visão mais clara das organizações e das formas de trabalhar. A ótica aristotélica é, também, compatível com a atual passagem da concepção homogênea das organizações para a concepção das organizações como entidades abertas, formadas de indivíduos que transitam por uma pluralidade de ambientes e que se comunicam através de redes complexas

Neste artigo, examinamos três temas do pensamento aristotélico que podem ajudar a informar a racionalidade do trabalho hoje. São eles:

- a prevalência da razão prática sobre a razão teórica na orientação do agir;

- a hierarquização das formas de trabalhar segundo o quantum de razão que requerem;

- a valorização dos resultados em detrimento dos processos.

" Professor Titular da Escola Brasileira de Administração Pública e de Empresas da Fundação Getulio Vargas. Professor Visitante Universidade de Paris (Sorbonne Nouvelle). "Senior Researcher" Universidade de Maryland, College Park. Doutor em Ciências - COPPE - Universidade Federal do Rio de Janeiro. M estre em filosofia - Instituto de Filosofia e Ciências Sociais da Universidade Federal do Rio de Janeiro. E-mail: hermano@ fgv.br. 


\section{0 domínio da sabedoria prática}

O primeiro paralelismo que podemos traçar entre o que a acontece nas organizações contemporâneas e a forma de pensar de Aristóteles é o da especificidade do conhecimento requerido para produzir e para administrar. O critério desse saber é duplo. Ele é dado pela natureza e pela razão. No que tange à razão, não é o conhecimento teórico que tem maior valor, mas a sabedoria prática adquirida com a experiência. Diz Aristóteles que podemos ter muitas teorias sobre a ciência da riqueza e da forma de administrá-la; mas para tal ciência, o fundamental, o obrigatório é a experiência. É experiência que rege "as partes úteis" da ciência da riqueza (POL. I, 11, 1258B).

Isso em nada diminui o valor do saber teórico. O saber teórico é o conhecimento das causas. ${ }^{1}$ Um saber que tem como finalidade dar "a razão de". ${ }^{2}$ Seu método é simples de ser descrito. Para agirmos racionalmente, devemos, primeiro, estabelecer qual o problema (MET. III, 1, 995). Fixado o problema particular (o experimentado), universalizamos a solução encontrada (a ciência) pela indução (análise) e dedução sucessivas (FIS, I, 1, 184).

Neste processo devemos respeitar os princípios básicos da lógica. O primeiro deles é o da não-contradição, que diz que uma coisa não pode ser e não ser ao mesmo tempo (MET. IV, 3, 1005). ${ }^{3} \mathrm{O}$ outro é o do terceiro excluído, que afirma que toda proposição válida é, necessariamente, verdadeira ou falsa. Os elementos do raciocínio lógico são:

- o juízo, que é o discurso que afirma ou que nega alguma coisa de alguma coisa (um predicado de um sujeito) (AN. POST. I, 24, 85A);

- o silogismo, que é o discurso no qual se estabelecendo algumas premissas se deriva algo diferente da premissa (conclusão) (AN. PRI., I, 24, 41'a);

- a indução, que é a passagem do particular para o universal (TOP. I, 12, 105);

- a análise, que é o processo que tem como resultado a divisão ou classificação (AN. POST. I, 31, 146);

- e a demonstração, que é o discurso que explica por que uma coisa é ou não é verdadeira (AN. POST. II, 3, 90).

Por mais perfeita que seja a lógica, a sabedoria teórica não pode nos ajudar quando se trata de saber como agir. Aristóteles diferencia a razão pelo seu fim, pela causa final a que ela se destina. Na razão teórica precisamos saber a conclusão, o fim a que queremos chegar, enquanto na razão prática precisamos saber o problema que queremos resolver. A conclusão da razão teórica é uma verdade. O que pensamos é verdadeiro. A conclusão da razão prática é uma indicação do melhor caminho para o bem, nosso e dos outros. O que pensamos é bom (THORNTON, 1982, p.63). ${ }^{4}$

O fim da ação humana, o propósito da vida particular, da administração dos negócios, do governo do Estado é diferente do fim do conhecimento puro, da theoria. Na vida prática queremos saber como agir. Queremos saber quais as razões para agirmos dessa ou daquela maneira. Tanto para a produção como para a administração da casa, dos negócios e da polis, o conhecimento requerido é diferente da racionalidade pura. O fim da polis é o bem viver. O fim da oikos (da casa: grego oikonomía, atos; latim oeconomia,ae) é a produção e a reprodução da

\footnotetext{
${ }^{1}$ As quatro causas são:

- a formal, o por que primeiro, a essência, o modelo;

- a material;

- a eficiente, o agente de onde vem o princípio do movimento;

- a final, para onde vai o princípio do movimento.
}

Por exemplo, na construção de uma casa, temos a causa eficiente; o agente que produz o objeto; a força propulsora - trabalho ou capital -; a causa material, do que a algo; do que a casa é feita, os materiais; a causa formal, como algo está feito, o modelo [a essência], o plano (não adianta juntar os materiais arbitrariamente); e a causa final, o fim para o qual o objeto se destina, a intenção de construir. (FÍS. I,1, 184a, 10). A causa formal e a final podem ser reduzidas a uma única (o fim é a essência e vice-versa) (MET. I, 3, 983) (MET. VIII, 4, 1044). O intelecto é potência (matéria) e ato (causa eficiente).

2 "O mais alto saber é contemplar o porquê" (AN. POST., I, 14, 79).

${ }^{3}$ Contra Heráclito (MET. XI, 5, 1062).

${ }^{4}$ Quando aplicamos um silogismo (se isso, então aquilo) à praxis, pensamos prioritariamente em regras e casos (como agir no caso de). Quando o fazemos à poiesis, pensamos prioritariamente em meios e fins (o que fazer para...). 
vida material (POL. I, 4, 1254 A). São propósitos diferentes do conhecimento contemplativo, do conhecimento teórico.

Aristóteles sustenta que a razão teórica e a sabedoria prática são mutuamente exclusivas porque a technê (a arte ou o conhecimento técnico) pertence ao reino da necessidade hipotética, enquanto a phronêsis (a sabedoria prática) pertence ao reino da escolha contingente. Quer ele dizer com isso que no domínio da technê, uma vez estabelecido um fim, o método lhe segue necessariamente. Só existe uma forma correta de produzir uma coisa (FIS. 200A 15, 2A). Já na razão prática (bouleusis), começamos por algo que desejamos (boulesis) e terminamos por uma escolha (proairesis) (ÉT. A NIC. 3. III). No domínio da phronêsis, o fim da ação é vago (o bem, o bem viver) e não determina por si só o caminho para se chegar a ele. O método tem que ser construído a partir daquilo que se tem: a sabedoria derivada do conhecimento e da experiência acumulados (ÉT. A NIC. 1114A).

O que nos faz agir é a alma, aquilo que nos anima. Para Aristóteles, a alma é tanto racional como não-racional. ${ }^{5}$ Por sua vez, a porção não-racional da alma é parte irracional (vegetativa) e parte obediente à razão (apetitiva, relativa aos desejos). As virtudes da alma racional são dianoéticas, são as virtudes do intelecto. As virtudes da alma não racional apetitiva são as virtudes éticas, as virtudes do controle dos apetites (ÉT. A NIC, I, 13, 1102). ${ }^{6}$ Pois é da sabedoria prática que nos vamos servir para trabalhar e administrar o trabalho. A ação humana depende da combinação de todos os poderes da alma: percepção, imaginação, raciocínio e desejo.

Para orientar o agir também não nos servem os sentimentos. As sensações não nos dizem o porquê (MET, I, 1, 981-2), e sem o porquê, sem o conhecimento das causas a ação não é razoável. O que estimula o intelecto prático é o objeto do apetite (DE AN. III, 10, 433 A 15 E SS). Não podemos nos livrar de ter impulsos e desejos - seria como treinar uma pedra para rolar morro acima - mas podemos controlá-los (ÉT. A NIC. II, 4, 1113A, 11). Os poderes nos são dados, mas cabe a nós combiná-los. Nós, os seres dotados de razão, somos responsáveis pelo que fazemos da nossa alma (ÉT. A NIC. III, 5, 1114B, 23-4).

Essa sabedoria pratica a phronësis, diz Aristóteles, nos leva ao justo meio, ao que é adequado, ao que é perfeitamente ajustado. O justo meio funciona para a justiça comum, na medida em que, embora os homens procurem retribuir o mal com o mal, a verdadeira justiça deve obedecer à proporção do dano ou da ofensa (ÉT. A NIC. III, 4, 1133A). O justo meio funciona da mesma maneira nas relações de troca, mas para isso é necessário haver um princípio de comensurabilidade dos diferentes trabalhos necessários à produção do bem ou serviço. A reciprocidade nos tratos comerciais supõe a equalização, o balanço do trabalho de cada um (POL. I, 11, 1258B). Aristóteles dá o exemplo do arquiteto e do sapateiro. Não se pode trocar uma casa - o trabalho do arquiteto - por um sapato - o trabalho do sapateiro. Nem faz sentido trocar a casa por muitos sapatos. Afinal, o que se faria com eles? Dessa impossibilidade de troca direta e da necessidade de um meio de ajustar a permuta dos bens, deriva o dinheiro (ÉT. A NIC. V, 5, 1133A). O dinheiro é uma convenção (nômisma, vem de lei, nomos). É um artificialismo necessário à troca. É o dinheiro, o salário, que equaliza a troca do trabalho pela recompensa, pelas condições de vida.

Há duas classes de termos médios: o termo médio de um objeto em si mesmo e o termo médio aferido em relação a nós, daquele que avalia (pros hemäs). É a esse segundo termo médio, qualitativo, a que Aristóteles se refere como orientador da justiça, da relação de troca, do agir. $\mathrm{O}$ termo médio que não é demasiadamente muito nem demasiadamente pouco.

\footnotetext{
${ }^{5}$ Para Aristóteles, a alma das plantas é viva (reprodutora); a dos animais é viva e sensível; a dos homens é viva, sensitiva e racional (DE AN. 414 a 29 415 a 13). Aristóteles dá o exemplo de potência, primeiro ato e segundo ato. Ele afirma que a habilidade para aprender é potência, ter aprendido é primeiro ato e usar o que se aprendeu é segundo ato. (DE AN. 412 a 9; 412 a 22) (GARRET, 1988, p.273).

${ }^{6}$ A razão é dada pela fração:

corpo

alma $\frac{\text { alma racional(virtudes dianoéticas) }}{\text { alma não racional } \text { alma obedienteà razão (apetitiva) (virtudeséticas) }}$

alma irracional (vegetativa)
} 
Também para o trabalho, o justo, o correto e adequado, é um meio-termo qualitativo (ÉT. A NIC., V, 5, 1133B). Os exemplos de que Aristóteles faz uso levam a concluir que o que mede o acerto nas decisões tem que ser determinado por nós mesmos, e que situações distintas requerem medidas distintas porque somos pessoas diferentes e desiguais e as situações que passamos são dinâmicas e mutantes (ÉT. A NIC. V, 5, 1133A). Isso parece ser um relativismo. Mas não é. A virtude aristotélica não está na escolha que é feita, mas na faculdade de escolher acertadamente. A sabedoria prática, a phronesis, é que é virtuosa (ÉT. A NIC. II, 5, 1106B, 1107A.).

Em Aristóteles, o julgamento do meio-termo deriva da doutrina das faculdades da alma. A parte desejante da alma inclui a cobiça (baixo ventre e ventre), o impulso (cólera) e o desejo. O desejo é mais acessível à razão, embora não o seja completamente porque podemos desejar o impossível. Agir racionalmente é agir não sendo movido nem por um excesso nem por uma carência. O meio-termo não é uma média matemática - não é uma medida, mas uma proporção qualitativa. Também não é uma mediocridade: é um extremo (ÉT. A NIC., II, 6, 1107A). É o equilíbrio perfeito entre os apetites e a razão (ÉT. A NIC., III, 5, 1114B, 29, 1139A, 24-6, 31-2). A virtude é uma excelência do meio-termo. É o resultado do balanceamento entre os sentidos e os princípios. A sabedoria prática é a ação racional a partir de razões, não de impulsos ou desejos.

Aprendemos a julgar pela experiência. Mas o desenvolvimento da phronesis, da sabedoria prática, não é simples e não é fácil. O que vem a ser essa sabedoria prática e como podemos chegar a ela requer um esforço de compreensão do que vem a ser o termo médio qualitativo e o que vem a ser a virtude, a excelência. Em última instância, a questão é a de determinar o que faz a sabedoria prática virtuosa. Pois o que a faz virtuosa é o seu fundamento, a base sobre a qual se erige. A phronesis é definida como uma disposição racional correta a respeito da ação sobre as coisas que são boas ou más para os homens.

Ora, para Aristóteles, a razão se reparte segundo os fins. É o fim a que se destina que faz com que a sophia, a alma teórica, a techné, a perícia produtiva, o nous, o intelecto que capta as intuições, a episteme, o conhecimento dedutivo, sejam diferentes. A razão prática, a alma calculadora, que é a porção da alma que aqui nos interessa, tem a sua especificidade no fato de captar a verdade a partir de um desejo, de um impulso e controlá-lo através da razão (ÉT. A NIC. V, 7, 1135A. 30-1).

É experimentando e raciocinando sobre o que nós e os outros experimentamos que chegamos à sabedoria. É a vivência que nos leva à habituação da razão prática (ÉT A NIC. II, 1, 1103B, 1422). A razão prática não se adquire na escola, porque não se trata de um controle puramente racional sobre os desejos que possa se perder quando a atenção é desviada, mas de um controle internalizado, uma habituação, uma segunda natureza. As três fontes da arete, da virtude, no sentido da virtù, da excelência, são: a natureza (physis), o costume (ethos) e a razão (logos) (POL. VII, 13, 1332A 40). O homem que não controla seus desejos (alratës) que se deixa levar pela incontinência (akrasia) não é razoável.

Aristóteles diz que a virtude é um exis, um esforço para apreender, para adquirir, para controlar. Uma atitude da razão para encontrar o justo meio. A virtude é uma disposição, mas uma disposição ativa, uma educação do espírito (CAT. 8B, 29). Aqui é preciso não confundir: o exis, em grego, o habitus, em latim não significa o mesmo que o hábito em português. O hábito está referido ao costume, o exis ao processo de se adquirir esse costume, habituação. Mediante a habituação atingimos o caráter. ${ }^{7}$ Controlamos nossa índole. O contrário do caráter é o vício (há pessoas que tem mau-caráter) não o mau hábito ou a fraqueza. O exis é diferente do habitus tal como é geralmente entendido na atualidade, na forma em que foi retomado por Pierre Bourdieu. Para Bourdieu o habitus é algo incorporado, algo inconsciente ("genesis amnesia"). Uma forma permanente de se estar, de se comportar, de sentir e de pensar (BONNEVILLE, 1997; BOURDIEU, 1977, 1990). Para Aristóteles é uma habilidade adquirida e uma faculdade. $\mathrm{O}$ exis não é um condicionamento, mas uma propriedade. $\mathrm{O}$

${ }^{7} \mathrm{O}$ caráter é a marca riscada ou gravada que distingue uma coisa da outra. 
condicionamento é imposto inconscientemente pelas situações, pelos outros, ou deliberadamente por nós mesmos. O exis gera, por repetição consciente ("acostumação" - ethos), o caráter (ithos). ${ }^{8}$

A sabedoria prática se dá em relação aos meios. Ela abrange os meios que levam aos fins determinados pela virtude se dirigindo ao indivíduo; da mesma forma como a política se dirige ao Estado (ÉT. A NIC., VI, 12, 1144A. 7-9). O horos, a norma da razão reta, vem prioritariamente da experiência, nossa e dos demais (ÉT. A NIC., VI, 10, 1143B 11-14). Não é um impulso (uma ação em que a razão é passiva) nem uma capacidade natural. Nenhuma virtude é boa em si. O que é bom ou mal é o ato, que deve ser contido, mantendo a alma em equilíbrio estável( ÉT. A NIC. II, 4, 1105A). É uma posição dinâmica, não alguma coisa que possa receber normas ou regras fixas. Estável não quer dizer estático.

O desejo deve ser mediado pela razão. No que se refere ao seu objeto, deve ser mediado pela prudência. No que ser refere aos meios, deve ser mediado pela escolha racional (a razão calculadora) (ÉT. A NIC., III, 5, 1114A). Não podemos mudar nossos desejos, apenas controlá-los. Também não podemos mudar nosso temperamento, mas podemos administrá-lo. A proháiresis indica o resultado de uma deliberação e expressa a conclusão do agente quanto à ação correta. É movida pelo que São Tomás de Aquino chama de desejo racional ou razão desejante. O desejo entra em acordo com a razão ao se deixar disciplinar e dirigir pelo reto hábito moral. Ao se caracterizar pela retidão, o desejo passa a corresponder diretamente à verdade, e é então um ato de vontade.

Trazendo aos dias que correm essa visão da sabedoria prática, prudencial, equilibrada entre a lógica e o impulso, é fácil ver como ela vem se aplicando às novas perspectivas sobre a transformação das organizações e das relações de trabalho. A orientação do agir, a racionalidade do trabalho e no trabalho passa por essa sabedoria. Pela adequação de meios e fins, pela acumulação de experiências, razões e reflexões sobre a experiência, produzindo a atitude prudencial. É um processo e uma conduta muito próximos daquilo que vem sendo a prática econômica e gerencial, principalmente no que se refere à superação do quantitativismo e do rigorismo teórico que marcaram o final do século XX.

Um segundo paralelismo entre o pensamento de Aristóteles e o que ocorre hoje nas tentativas, nem sempre bem sucedidas, de dar racionalidade ao trabalho, reside na diferenciação do valor do trabalho pelo quantum de razão, prática, técnica ou teórica, que ele exige.

O eixo do pensamento aristotélico é de que, sendo a capacidade de raciocinar a essência da humanidade (ÉT. A NIC., I, 7, 1097 B 24-98 A 21), quanto mais elevado o raciocínio exigido, quanto mais especializado e amplo, maior o valor que deve ser atribuído à ocupação e à função.

Para considerarmos a diversidade das exigências do raciocínio aplicado ao trabalho na forma do realismo aristotélico, teremos que ver o trabalho como ele é no mundo real. Isso não é fácil porque ao longo dos três últimos séculos, quando nos referimos ao trabalho, temos pensado em um construto racionalista a que denominamos "o trabalho em geral". Marx (1971, I, p.1) chegou a lamentar que Aristóteles não tivesse alcançado esse conceito universalista do trabalho. Mas ele nem poderia, porque o trabalho no tempo de Aristóteles se dizia de muitas maneiras. Cada forma de trabalhar circunscrevia uma racionalidade, um status e uma ética.

Sem entrar nos detalhes do esquema referencial do trabalho para cada filósofo ou historiador, uma tentativa de compreender o entendimento sobre a atividade humana na Grécia nos dá várias categorias. A partir da divisão entre o esforço com produto tangível, ${ }^{9}$ poiesis, e o esforço com resultado intangível, temos (VERNANT, 1965);

1. uma divisão dessa poiesis, "fabricação", em:

\footnotetext{
${ }^{8} \mathrm{~A}$ virtude que deriva da razão prática não procede nem da natureza; isto é, não é passiva, nem de algo fora da natureza. Ela não é algo artificial, inteiramente construído pelo homem. (ET. A NIC. II, 1103A, 24-5). Ela é uma segunda natureza, adquirida pela habituação (ET. NIC. II, 1-3,1103B, 23-5). A habituação não é a virtude, mas o processo de se adquirir a virtude pelo poder da razão (ET. A NIC. I, 7, 1097B, 24-1098A, 4).

${ }^{9}$ Poiesis corresponde ao inglês "make" e praxis a "do". Na poiesis o fim é separado do meio, na práxis o meio e o fim têm a mesma natureza (ET. A NIC. VI, 5, 1140B 4-06).
} 
- esforço penoso - ponos, a lida diária e constante, o esforço que não gera bens diretamente. Foi o esforço de Hércules, é o esforço do escravo e do oprimido, mas pode não ser produtivo;

- esforço qualificado - technê - atividade do artesão (técnica), fabricação;

- esforço criativo - ergon (dispêndio de energia), o trabalho que gera resultados, como a atividade de produção primária, e a atividade financeira (chrematon). Inclui o produto da areté (a virtude, a excelência) de cada um, e o produto da poiesis;

2. uma divisão do esforço com resultado intangível em:

- administração do viver ou o viver eticamente - praxis, o cuidado de si mesmo. A prattein é uma atividade natural, sem propósito produtivo, algo que se cumpre. É o contrário da poiesis;

- contemplação e ciência - theoria;

- esforço desinteressado - em Homero, inclui o esforço do demiurgos - atividades realizadas fora do oikos, em favor do demos (todos). Em favor dos aedos, dos artesãos, mas também dos adivinhos e dos arautos, que não produzem nada. Inclui a gestão da polis, a gestão social e, talvez, a luta pelo poder - política.

Em cada momento da evolução do pensamento grego o conteúdo dessas categorias sofre pequenas mudanças, mas a base mais segura para o seu entendimento parece ser a aristotélica. Aprendemos com Aristóteles que tanto o ponos como o ergon não são esforços realizados de per si, mas em vista de outros interesses: são instrumentalizações. Que a poiesis, corresponde à geração de um valor exterior à produção, um valor utilizável por outros, em que o produto está a serviço do usuário e não do produtor. $\mathrm{O}$ artesão fabrica (poiesis) para um usuário que agirá (praxis) (COTTA, 1987).

A praxis corresponde à geração de um valor utilizável em si mesmo. Por exemplo, quando estudamos, "produzimos" um valor que é útil em si mesmo, um valor, o saber, que é útil para quem estuda e para o estudo. O mesmo se passando com a conduta, de acordo com a ética (VERNANT; VIDAL-NAQUET, 1988) e com outras atividades não utilitárias.

O comércio e a atividade financeira tratam da riqueza, que nada tem a ver com ponos ou a poiesis. A relação entre trabalho e riqueza é recente. Não faria nenhum sentido para Aristóteles, que separa o valor de uso - a necessidade que temos de um bem - do valor de troca - que é tratado na cremática (POL. I, 9, 1257A). ${ }^{10}$

Aristóteles é conhecido por considerar o trabalhador (o escravo) como instrumento (POL.I, 3, 1253B). Mas não é bem assim. O que faz é separar a vida ativa da vida contemplativa. Separa o trabalho dos que concebem do daqueles que fazem (praticói). Considera o trabalho ignóbil quando separado da concepção (MONDOLFO, 1968). Pensa que os que se dedicam ao ponos e ao ergon não são livres: são escravos da necessidade. Que mesmo o artesão que possui tecné não é um criador: é um imitador da forma que existe no espírito. MEDA (1995) vê uma degradação do ser humano (artesão, escriba, jornaleiro) dominado por sua tarefa e pela remuneração (POL. III, 4, 1278A 6-9). Para Aristóteles, os banausoi, como não trabalhavam para o interesse público, não eram cidadãos por completo (GORZ, 1988).

Essa classificação das formas de trabalhar deixa claro duas verdades iniludíveis. A primeira é que ao longo da história humana, cada época empresta um valor e uma importância diferente ao trabalho. A segunda, que existem - e sempre existiram - muitas formas de trabalhar. Que, em geral, o conceito de trabalho é um hiato que precisa ser superado. Como explicou Hannah Arendt (1999) e, depois dela, Baudrillard (1975) contestando Marx, o conceito de trabalho em geral é um equivoco ou, pelo menos, um alimentador de equívocos desde que Locke o utilizou pela primeira vez. Não só Locke, mas Ricardo, Adam Smith, Marx e os que se seguiram, fizeram uso desse conceito, até que o texto-denúncia de Arendt levou à consideração prática e acadêmica o fato de que o trabalho em geral é um fenômeno que nunca teve realidade.

Como é fácil de ver, esse equívoco se reflete na apreciação que fazemos hoje do trabalho. Muito da reflexão e das ideologias sobre o trabalho que aí estão se referem a um construto abstrato, a uma não-realidade, a uma

\footnotetext{
${ }^{10}$ A cremática ou a crematologia, khrémata, trata das riquezas, dos bens.
} 
entidade inexistente. Quando nos fixamos na análise do binômio racionalidade-trabalho a partir do conceito do trabalho em geral, esse artificialismo mostra sua disfunção. Se, no entanto, retomamos a apreciação do esforço humano no entendimento e na forma aristotélica, temos uma visão mais clara do que realmente acontece nas organizações.

Nas passagens em que explica as relações de trabalho, Aristóteles diz que a primazia dentre os ofícios é dada pelo quantum de razão que requerem. ${ }^{11}$ Isto significa que ele já entendia que a recompensa e as oportunidades são maiores para as ocupações que exigem mais raciocínio e mais técnica. Que as formas de trabalhar menos intelectuais: o trabalho pesado, o trabalho servil, o trabalho vil ${ }^{12}$ são inferiores. Que a primazia do conhecimento justifica a prioridade das artes mecânicas sobre a força física (POL. I, 10, 1259 $)$.

Ora, isso tem tudo a ver com as dificuldades que temos, hoje, no mundo inteiro; tentando superar, não só em termos de destravar uma legislação homogeneizadora - que obriga ao equilíbrio linear no tratamento de fenômenos diferentes - como o descarte inevitável de pessoal não qualificado, isto é, na valorização da tecné e na evidente falta de futuro para o trabalho-ponos.

Também na administração, nas funções executivas, é possível traçar um paralelo entre as idéias de Aristóteles e a atualidade. Para Aristóteles a relação entre a direção e o trabalho, entre aquele que manda e aquele que obedece, é regida por uma hierarquia derivada do conhecimento e da experiência. De forma que não só a hierarquia das ocupações é dada pela razão: também a hierarquia funcional deriva da sabedoria prática. É a sabedoria prática que vai informar o nível dos executivos no mundo dos negócios de Estado, dos negócios particulares, da administração da casa (economia), da regência sobre quem trabalha.

Já desde a mais alta função, a do exercício do poder político sobre homens livres e iguais, é a razão que vai determinar a hierarquia (POL., I, 4, 1253A). Entre os homens da primeira categoria, como os magistrados, o critério da divisão deve favorecer os que tenham melhores hábitos, os que tenham absorvido a experiência da vida, os que tenham a linguagem mais elaborada, os que tenham educação, e os detentores de honrarias; isto é, os que tenham tido reconhecimento.

Para Aristóteles, como para os gregos em geral, a vida solitária é impensável. É da natureza dos seres humanos se associarem (POL. 1252B 25 - 1253A). A administração dos homens, dos outros seres dotados de razão, é a mais importante das tarefas. A hierarquia das funções que podemos desempenhar na vida prática é dada pela razão. A ordem de distribuição dos níveis de relevância obedecem a esse critério, indo da administração dos homens - inclusive da auto-administração - à administração das coisas inanimadas, passando pela administração dos demais homens livres, e dos escravos (POL. I, 11, 1258B). ${ }^{13}$

Aristóteles pensa que o objetivo do poder real, natural, exercido sobre homens livres e desiguais, do poder exercido nos negócios, tanto do Estado como particulares, é dominar. O governo da casa (oikonomía,atos) deve ser compatível com o governo do Estado (POL. I, 13, 1260ª). Nas relações de permuta, no comércio, é natural que o gestor procure criar monopólios. Nos negócios de Estado os governantes procuram fazer o mesmo, monopolizando a força (POL. I, 11, 1258B). Ele louva o uso da inteligência, seja ela o logos e o saber erudito como a adivinhação -, ou saber prospectivo - do qual faz uso Tales de Mileto para determinar a melhor época

\footnotetext{
${ }^{11} \mathrm{O}$ conhecimento sobre o salário e o trabalho é uma das partes da ciência da riqueza. Uma ciência que trata dos afazeres relativos às permutas, à criação dos animais e à agricultura. (POL. I, 10, 1259A) e, também, dos afazeres extrativos (POL. I, 11, 1249B). No que se refere às permutas, os conhecimentos principais são o comércio, a usura (as finanças) e o salário. O salário se refere aos ofícios.

${ }^{12}$ Isto é, o trabalho que não requer nenhuma virtude especial.

13 A ordem hierárquica é a seguinte:

administração dos homens

autodesenvolvimento (auto-administração)

homens livres

escravos

virtuosos

comuns

administração das coisas inanimadas
} 
para adquirir bens e depois revendê-los -, seja a astúcia (métis) do siciliano de Siracusa que especula com mercadorias (POL. I, 11, 1258B).

Aristóteles percebe claramente o valor do trabalho qualificado e da especialização. Vê as vantagens do trabalho realizado por um só homem (POL. II, 11, 1273B 9, 199A 40) qualificado especificamente (POL. VII, 8, 1328B, 25), e argumenta que o estatuto do operário livre é diferente do estatuto do escravo porque o trabalho que aquele executa produz um objeto de troca (ergon) enquanto o escravo, simplesmente, prolonga a mente e o corpo do mestre. Como instrumento, o que ele faz é um serviço menor (ponos). Ele é uma "parte" de outra pessoa. A parte servil do mestre. (ÉT. A NIC. V, 6, 1134B 12). A razão do escravo não lhe pertence. É o senhor que detém o logos, a razão superior. O escravo é incompleto, defeituoso, é mal formado por natureza (POET., 15,145 A 20).

É sempre o uso da razão que determinará a hierarquia entre os seres humanos. Mesmo no último nível da administração, no poder despótico exercido sobre aqueles que não são livres, sobre os escravos, a razão tem um papel decisivo. Para Aristóteles, todos, desde os senhores até os escravos, são dotados de raciocínio (POL., I, $13,1259 \mathrm{~B}, 1270^{\mathrm{a}}$ ). Mas o raciocínio é necessário diferentemente para cada estrato. Os seres feitos para obediência, devem ter virtudes diferentes. As virtudes dos senhores estão ligadas principalmente à alma racional (são virtudes dianoéticas); a dos demais, em graus diferentes, são relacionadas à alma apetitiva (virtudes éticas). Por isso, nas hierarquias que Aristóteles postula, a primazia é dada aos homens capazes de melhor exercer as faculdades da alma racional.

Os critérios que utiliza na formação de hierarquias são relacionados à sabedoria prática. No que se refere à natureza, existem três critérios de hierarquia. O critério biológico (homens, mulheres contra a natureza, ${ }^{14}$ as mulheres por natureza), o da experiência (idoso, jovem) e o critério da natureza (perfeito, imperfeito) ${ }^{15} \mathrm{~A}$ combinação desses fatores concentra o poder sobre o homem livre, senhor da casa e dos negócios (POL. I, 13, $1258 \mathrm{~B}, 1260 \mathrm{~A}){ }^{16}$

Aqui também se vê que o que confere autoridade é a razão. A virtude daquele que comanda, deve ser maior que a dos demais. O que obedece necessita naturalmente de pouca virtude A mulher é naturalmente mais fraca, o filho ainda é incompleto, o escravo necessita de pouca virtude. O escravo é escravo por natureza, e alguém predestinado à incompletude (POL. II, 13, 1259B, 1260ª)

Antes de discutirmos a posição aristotélica sobre a escravidão, cabe uma observação sobre o que ele pensa a respeito das mulheres. Além da óbvia circunstância de ter vivido em uma época em que a mulher tinha um papel social e moral muito reduzido (a reprodução da espécie e o cuidado doméstico) ou talvez por isso mesmo, a percepção de Aristóteles é ambígua. Ele diz que a mulher é inferior aos homens, mas não a considera defeituosa. Ela é inferior porque não tem a autoridade (é akyron) (POL. I, 13, 1260A 13). Essa falta de autoridade, diríamos nós hoje, é uma resultante cultural. Algo que deriva da opressão societária, não da natureza da mulher. Seja como for, aos olhos de Aristóteles isso a torna inapta não só para mandar, mas, principalmente, para controlar a si mesma. No entanto, ele não parece muito certo nem dessa inferioridade nem da inaptidão para o trabalho. Tanto que postula que as meninas tenham uma educação pública, com objetivo de desenvolver a castidade, a beleza e, principalmente, o gosto do trabalho sem avareza (RET. I, 5, 1361A 6). Julgar que a mulher possa aprender, alem de ornar o mundo; que possa se dar ao trabalho desinteressado, não a coloca em um plano inferior, mas em um plano diferente do dos homens, sejam livres ou escravos.

Assim, retornamos ao último paralelismo entre o realismo aristotélico e atualidade: o que se encontra na polêmica argumentação sobre o escravo.

\footnotetext{
${ }^{14}$ A causa final das mulheres é diferente da dos homens; isto é, as mulheres têm um propósito de estar no mundo diverso.

${ }^{15}$ A hierarquia resultante da combinação desses critérios é a seguinte: homem idoso perfeito; homem idoso imperfeito; homem jovem perfeito; homem jovem imperfeito; mulher idosa perfeita; mulher idosa imperfeita; mulher jovem perfeita; mulher jovem imperfeita.$$
\begin{array}{ll}
{ }^{16} \mathrm{O} \text { esquema é o seguinte: } \\
\text { as pessoas livres } \frac{\text { filhos (poder de fato, real) }}{\text { mulher (poder civil, natural) }}
\end{array}
$$ 
De novo, aqui se vê que o conhecimento e a vivência de uma época não são transferíveis. Da mesma forma que conceitos como o da homogeneidade do trabalho e o da equalização do valor-trabalho não podem hoje serem vistos sob a ótica de meados do século passado, o que Aristóteles diz sobre a escravidão e sobre o escravo só nos pode ser útil na medida em que aponta para conceitos e verdades que passam despercebidos quando se discute a situação do trabalhador contemporâneo.

Para Aristóteles, o trabalho nem é racional nem conduz à eticidade. As faculdades da razão servem para fabricar e para administrar, para mandar e para saber obedecer. O trabalho é útil porque nos livra da penúria, da miséria (POL. I, 7, 1255B - 1257A). Ele pensa que o ser humano completo é autárquico, é livre. Não trabalha, ou não deve trabalhar, no sentido que damos ao termo hoje em dia, a menos que isso seja inevitável ou que a atividade que exerça, como a atividade do demiurgo, seja uma obrigação moral e não uma necessidade material.

O desprezo manifesto pelos gregos em relação ao trabalho vem de uma constatação lógica. O sentido que emprestam ao trabalho não é um sentido transformador, de uma atividade que se contrapõe à natureza, mas o de adequação ao que a natureza e a vida nos reservam. Quem trabalha está sujeito à matéria, está sujeito às resistências impostas pela matéria que ele transforma. Essa sujeição, tanto a que o condiciona diretamente, como a que o obriga a condicionar outros homens que trabalhem para ele, tira sua liberdade. Por isso, para os gregos, a existência do que hoje chamaríamos de trabalhador é heterônima e, portanto, depreciada.

Para Aristóteles, a escravidão é natural porque racional, e é justa porque é razoável, porque adequada às necessidades sociais. Os cidadãos atenienses podem cuidar do governo da polis porque os escravos trabalham para mantê-los. É uma troca. Da mesma forma que a constituição perfeita "jamais fará de um operário manual um cidadão" (POL. III, 3, 5, 1276B - 1277A). O escravo é um predestinado. Ele não é um utensílio inerte. É um instrumento animado - com algo que o anima. ${ }^{17}$ Como os animais, tem alma, tem sentimentos. Como ser humano, tem raciocínio (POL. II, 11, 1258B). Ele não é um animal, mas um instrumento específico, tal como o barco, que é um instrumento que serve para navegar, e o leito, que é um instrumento que serve para deitar. ${ }^{18}$ Ele é um bem adquirido. É um objeto de propriedade (ktema) de outro ser humano. Pertence ao mestre que pode utilizá-lo, mas que não deve abusá-lo (POL., I, 4, 1253B).

O escravo não é um animal, mas está quase no plano de um animal. Existem homens livres e existem escravos; como existem animais selvagens, que não se pode domesticar, e animais domésticos. A força física está nos animais de carga e nos escravos (POL.I, 5, 1254A). Para Aristóteles, é natural (racional e justo) haver comandantes e comandados. Aqueles que devem obedecer têm uma disposição natural (racional e adequada) para a obediência. Subentende-se que os escravos não têm a parte racional da alma, ${ }^{19}$ por isso estão predestinados a servir.

Os argumentos de Aristóteles sobre a natureza da escravidão, olhados a partir do século XXI, não se sustentam. Mas chamam a atenção para um fato importante no momento em que o trabalho se transforma e que, nas modalidades que conhecemos desde a Revolução Industrial, caminha para a extinção. Quando Aristóteles argumenta que o escravo é escravo por natureza ele aponta, também, em outra direção: ele está dizendo que quem não é escravo por natureza, não pode ser escravo. Que escravizar um homem livre é agir contra-natura.

Transpondo para os dias de hoje a argumentação, significa dizer que obrigar, sob pena da execração pública e da miséria, uma pessoa autônoma, um ser humano livre, ao trabalho penoso e não criativo nos campos, nas fábricas e nos escritórios é uma monstruosidade. É supor que aquela pessoa, aquele trabalhador, ou é alguém que não tem condições intelectuais a não ser para obedecer, que é um escravo por natureza, ou, pior, que é um ser livre, que, contra a sua natureza, foi escravizado.

\footnotetext{
${ }^{17}$ Platão, Aristóteles e, até mesmo, Giordano Bruno acreditavam que o movimento celeste estava baseado em um princípio anímico. Só com Kleper, já no sec. XVII (e a partir de Descartes, que queria o homem como "maître et possesseur de la nature") a idéia da "alma dos planetas" se vê substituída por uma teoria matemática (CASSIRER, 1955).

${ }^{18} \mathrm{O}$ leme é um instrumento inanimado, mas o timoneiro - escravo ou livre - é um instrumento animado (POL. I, 4, 1253B)

19 “Alguns têm corpos livres, alguns têm alma” (POL.I, 5, 1254B).
} 
Um segundo ponto que merece reflexão é que o escravo é um instrumento de ação (práxis), não de produção (poïesis). Ele serve de instrumento, mas tem a dignidade humana. É apenas alguém como uma criança, que não pode governar a si mesmo. É um executante de serviços para o mestre que o orienta. O mestre necessita do escravo como esse do mestre. A cítara não toca sozinha. O músico sem a cítara, o mestre sem o escravo, de nada serve (POL., I, 4, 1253B). Seria de se perguntar se, hoje, a substituição dos trabalhadores pelos instrumentos de controle numérico faz dos gerentes mestres de escravos mecânicos.

Por último, podemos considerar que, para Aristóteles, embora a faculdade de comandar seja dada pelo nascimento (POL., I, 5, 1254A), nem todos os homens são capazes de se governarem, de governarem seus desejos e suas emoções (POL, I, 4, 1253B). De novo aqui a sabedoria prática é o que protege e distingue o ser livre. O que nos leva a ponderar que tanto no tempo de Aristóteles como agora - no mundo da ambição desenfreada, do consumismo, da anestesia das drogas -, quem não sabe impor a alma racional sobre a alma apetitiva, quem não sabe se governar é um escravo dos seus desejos. É um escravo por natureza.

\section{0 racional e 0 razoável}

Vivenciamos uma realidade inteiramente diferente daquela experimentada por Aristóteles. Na raiz da atitude prudencial que ele propunha estava a polis e a administração de homens e de coisas tão distantes de nós como a lança do guerreiro está distante da bomba de fusão. Na raiz do realismo prudencial contemporâneo está o cansaço do romantismo insolente, anterior aos acontecimentos de 11 de setembro. Está, também, a manifesta precariedade estrutural de empresas e organizações governamentais, demonstrada nas crises econômica e moral em que o mundo globalizado está imerso.

Esta breve incursão ao mundo aristotélico nos mostra algumas possibilidades para interpretar e entender o nosso próprio mundo. Primeiro, o realismo - ou pelo menos, o anti-idealismo - parece convir melhor à explicação de parte do que acontece ao trabalho nas organizações abertas, fragmentadas, facilmente expostas à dissolução e à fusão, do que outras abordagens. Segundo, o domínio crescente da sabedoria prática parece ser uma reação ou uma contrapartida ao fracasso retumbante dos esquemas quantitativos de explicação da economia e de orientação do agir gerencial. Terceiro, a ordenação do trabalho em suas múltiplas formas incluindo a obsolescência do emprego - e o imperativo do conhecimento e da informação para a conquista e manutenção da possibilidade de trabalhar guardam evidentes paralelos com as hierarquias fundadas na razão qualificadora de Aristóteles. As justificativas para o aviltamento do trabalho, que recorrem tanto à sua dispensabilidade como à instrumentalização do trabalhador, nada ficam a dever ao arrazoado aristotélico sobre o escravo.

Esperamos todos que o conhecimento e a informação levem a uma convivência mais sábia na vida e nas organizações. Que o esforço penoso, a labuta, o ponos, seja substituído pelo esforço criativo, pelo trabalho digno, pelo ergon. Hoje, queremos que o escravo encarnado no trabalho sem dignidade, seja, finalmente, visto como uma ocorrência contra-natura, como uma transgressão ética, como uma imoralidade. Talvez uma maior atenção para a sabedoria pratica, para a maneira de adquiri-la, pelo exercício da reflexão sobre o que realmente acontece e não sobre o que deveria idealmente acontecer nos ajude a progredir nesse sentido.

Aristóteles, que foi o artífice da lógica e do raciocínio preciso, sabia que a condução da vida se dá em outra esfera. Que o racional e o razoável não são a mesma coisa. Que o racional é o que pode ser entendido, enquanto o razoável é o que é dotado de razões. As fontes do razoável não são a lógica e a impassibilidade. São a experiência, a opinião, as crenças, a inspiração (THEVENOT, 1989). Não podemos falar de cálculo razoável como não podemos falar de sentimento racional. E isso precisa ser entendido, o pensamento aristotélico merece ser recuperado, porque ao pensarmos no destino do trabalhador é melhor termos razões do que sermos friamente racionais. Só assim poderemos esperar que a ordenação do trabalho seja feita em moldes mais humanos daqueles que assistimos nos últimos tempos. 


\section{Referências bibliográficas}

ARENDT, Hannah. A condição humana. Rio de Janeiro: Forense Universitária, 1999.

ARISTÓTELES. The works of Aristotle. Reino Unido: Encyclopaedia Britannica Inc., 1952; Ét. a Nic. = Ética a Nicômaco; Met. = M etafísica; Fís.= Física; Pol. = Política; Ret. = Retórica; De An. = Da alma; An. Pri. = Primeiros Analíticos; An. Post. = Analíticos Posteriores; Cat. = Categorias; To. Tópicos; Poét. = Poética.

BARNES, J.(Org.). The Cambridge companion to Aristotle. Grã Bretanha: Cambridge University Press, 1995.

BAUDRILLARD, J. Le miroir de la production. Paris: Galilée, 1975.

BERTI, E. Aristóteles no século XX. São Paulo: Loyola, 1997.

BONNEVILLE, L. Introduction a la sociologie de Bourdieu: du rôle des notions d'habitus et de champ dans l'approche de Bourdieu. Disponível em: <http://www.generation.net/ elbonne/luc/travail9.htm> Em:1997.

BOURDIEU, P. Outline of a theory of practice. Richard Nice, trans. Cambridge: 1977.

The logic of practice. Stanford: Stanford University Press, 1990.

CASSIRER, E. Las ciencias de la cultura. M exico: Fondo de Cultura Económica, 1955.

COTTA, A. L'homme au travail. Paris: Fayard, 1987.

GARRET, J. E. Persons, kinds and corporations: an Aristotelian view. Philosophy and Phenomenological Research, v.49, n.2, Dec. 1988.

GORZ, A. Métamorphoses du travail: quête du sens. Paris: Éditions Galilée, 1988.

LEAR, J. Aristotle: the desire to understand. Grã Bretanha: Cambridge University Press, 1994.

MARX, K. 0 capital. Rio de Janeiro: Civilização Brasileira, 1971.

MAUSS, M. The notion of body techniques. In: (translated by Ben Brewster) Sociology and psychology: essays. London, Boston and Henley: Routledge and Kegan Paul, 1979.

MÉDA, D. Le travail, une valeur en voie de disparition. Paris: Aubier, 1995.

MONDOLFO, R. 0 homem na cultura antiga. São Paulo: Mestre J ou, 1968.

MURPHY, J. B. The moral economy of labor, Aristotelian themes in economic theory. EUA: Yale University Press, 1993.

ROWE, C. Introducción a la ética griega. México: Fondo de Cultura Económica, 1993.

THÉVENOT, L. Equilibre et rationalité dans un univers complexe. Revue économique, mars. 1989.

THORTON, M. T. Aristotelian practical reason. Mind, v.91, n.361, jan. 1982.

VERGINIĖRES, S. Ética e política em Aristóteles. São Paulo: Paulus, 1999.

VERNANT, J. P. Mythe et pensée chez les grecs. Paris: Maspéro, 1965.

VERNANT, J. P.; VIDAL-NAQUET, P. Travail \& esclavage en Grèce ancienne. Bruxelas: Éditions Complexe, 1988. 